\title{
Erratum to: Time-Resolved In Situ Measurements During Rapid Alloy Solidification: Experimental Insight for Additive Manufacturing
}

\author{
JOSEPH T. MCKEOWN,,${ }^{1,5}$ KAI ZWEIACKER, ${ }^{2}$ CAN LIU, ${ }^{2}$ DANIEL R. \\ COUGHLIN, ${ }^{3}$ AMY J. CLARKE,${ }^{3}$ J. KEVIN BALDWIN, ${ }^{4}$ JOHN W. GIBBS, ${ }^{3}$ \\ JOHN D. ROEHLING ${ }^{1}$ SETH D. IMHOFF ${ }^{3}$ PAUL J. GIBBS, ${ }^{3}$ \\ DAMIEN TOURRET, ${ }^{3}$ JÖRG M.K. WIEZOREK, ${ }^{2}$ \\ and GEOFFREY H. CAMPBELL ${ }^{1}$ \\ 1.-Materials Science Division, Lawrence Livermore National Laboratory, Livermore, CA 94550, \\ USA. 2.-Department of Mechanical Engineering and Materials Science, University of Pittsburgh, \\ Pittsburgh, PA 15261, USA. 3.--Materials Science and Technology Division, Los Alamos National \\ Laboratory, Los Alamos, NM 87545, USA. 4.-Center for Integrated Nanotechnologies, Los Ala- \\ mos National Laboratory, Los Alamos, NM 87545, USA. 5.—e-mail: mckeown3@llnl.gov
}

\section{Erratum to: JOM}

DOI 10.1007/s11837-015-1793-x

Due to an error during production, the authors' names appeared incorrectly in the original PDF version of this article. They have since been updated. 